\title{
Probe-free label system for rapid detection of Cronobacter genus in powdered infant formula
}

\author{
Shiqian $\mathrm{Fu}^{\dagger}$, Yujun Jiang ${ }^{\dagger}$, Xia Jiang, Yueming Zhao, Sihan Chen, Xinyan Yang and Chaoxin Man*
}

\begin{abstract}
Cronobacter species previously known as Enterobacter sakazakii poses high risks to neonates and infants. In this work a rapid detection method was developed which combined loop-mediated isothermal amplification with lateral flow assay for detection of Cronobacter species in powdered infant formula. The fast amplification reaction without betaine was established and capable of performing DNA replication within $25 \mathrm{~min}$. Based on the novel probe-free labeling methods, we established a lateral flow assay to capture the specific loop-mediated isothermal amplification amplicons which were labeled with fluorescein isothiocyanate and biotin. And the final detection time of this system was within $40 \mathrm{~min}$. The false positive results of the lateral flow assay induced by primer dimer tagged with fluorescein isothiocyanate and biotin were eliminated by Taq single strand DNA binding protein ( $4 \mathrm{ng} / \mathrm{\mu L}$ ). Simultaneously, the efficiency of the fast loop-mediated isothermal amplification assay was achieved. By injection of Taq SSB into the amplification assay as a replacement for betaine, the novel probe-free method could detect Cronobacter species with high specificity and sensitivity at the detection limit in PIF of $10^{1} \mathrm{cfu} / \mathrm{g}$. Our overall strategy has excellent potential in the rapid diagnosis of Cronobacter species label-free by integrating loop-mediated isothermal amplification and lateral flow assay.
\end{abstract}

Keywords: Loop-mediated isothermal amplification, Probe-free label based lateral flow assay, Cronobacter species, Powdered infant formula

\section{Introduction}

Cronobacter species (Cronobacter spp.) isolated from plant-based food products, previously known as Enterobacter sakazakii, are foodborne pathogens that pose a high risk of infection to neonates as well as immunocompromised individuals causing meningitis, necrotizing enterocolitis, and bacteremia (Susan and Forsythe 2011), and the fatality rate is about $40-80 \%$ (Yan and Fanning 2015). Meanwhile, all Cronobacter spp., except C. condimenti, have been associated with human infections (Cruz-Córdova et al. 2012). It has been reported that the powdered infant formula (PIF) is the main source of their infection (Song et al. 2016). And recent research based on

\footnotetext{
*Correspondence: mcxwh2006@qq.com

${ }^{\dagger}$ Shiqian Fu and Yujun Jiang contributed equally to this work

Key Laboratory of Dairy Science, Ministry of Education, College of Food

Science, Northeast Agricultural University, Harbin 150030, China
}

international microbiological standards suggested that all species of Cronobacter must be absent in 10 grams of PIF (Odeyemi and Sani 2016). In addition, WHO (2007) has classified Cronobacter together with Salmonella as group A pathogens associated with PIF with clear evidence of illness in infants. Therefore, appropriate technologies to monitor Cronobacter spp. contaminated raw materials and products, especially in PIF is of great significance (Gautam et al. 2015).

The traditional cultural and biochemical-based methods are tedious and require skilled personnel and time (Blažková et al. 2009). Thus rapid methods are viewed as alternative means to detect and monitor Cronobacter spp. Nucleic acid amplification methods including PCR (Moraes and Maruniak 1997; Chen et al. 2015), multiplex PCR (Gordon et al. 2015; Zhang et al. 2015), real-time PCR (Cecilia et al. 2015; Mai et al. 2015) have attracted the attention of a plethora of engineers and scientists due 
to their relatively specific and accurate characteristics (Tafelski et al. 2015), but the limitations of their thermal cycling, complicacy and low level sensitivity impedes its applicability in rapid and routine monitoring of pathogens (Cornelissen et al. 2016). An easy method to operate loop-mediated isothermal amplification (LAMP) developed by Notomi in 2000 showed attractive potential and sufffered the problems common in complicated reactions with the inhibitory components extracted from the crude samples (Notomi et al. 2000). Recent years, LAMP has been successfully applied to detection for pathogens, and a simple heating device has been employed at a fixed temperature with an typical amplification time of 40-60 min to produce large amounts of DNA to obtain a detection limit of $10^{1}-10^{2} \mathrm{cfu} / \mathrm{g}$ by agarose gel electrophoresis (AGE) analysis (Hu et al. 2009; Fan et al. 2012).

To detect the LAMP products, lateral flow assay (LFA) have been well used as a replacement for carcinogenic ethidium bromide (EB) and inaccurate dyes due to its rapid, convenient, visual and accurate features (Wang et al. 2013; Chen et al. 2016). Previously, the LAMP amplicons were obtained at a stable temperature, hybridized with the fluorescein isothiocyanate (FITC)-labeled probe based on the base-pairing rule and developed the results on the LFA (Ding et al. 2010; Wang et al. 2013). Then amplicons double labeled with FITC/biotin were captured by streptavidin (SA)-tagged gold nanoparticles (AuNPs) which appeared visible band in the $\mathrm{T}$ line of the strip. Thus, the LAMP-LFA method based on probehybridization was successfully applied in bio-diagnostics area. Simultaneously, the complicated instruments were not needed and the detection results could be observed in a short time.

Nevertheless, the utilization of FITC probe induces nonspecific amplification and generates false positive results. Therefore, it is necessary for a label-based system to eliminate probe-hybridization. Recently, a novel probe-free label system has been reported in which the double labeled FITC/biotin LAMP amplicons captured by AuNP-based assay are visible in the LFA (Najian et al. 2016; Zhang et al. 2015). However, the 4-6 sets of LAMP primers increase the chances of obtaining spurious amplification products primarily because of the formation of the primer dimers that consumed the reaction components. The pioneer work by Brownie et al. first employed a sequence of additional nucleotides (a Tail) at the $5^{\prime}$ ends of amplimers to eliminate the primer dimers in PCR (Brownie et al. 1997), in which the work they did complicated the simplicity of the detection system and increased the risk of false results due to improper design. While some investigations have been done by using the single strand DNA binding (SSB)-like protein to resolve the problem in PCR assay (Nimitphak et al. 2008; Tian et al. 2014). Furthermore, the thermally stable Taq SSB protein enables to selectively combine the protein with primers and reduce or eliminate the dimer formation, thus it can be applied in the LAMP assay to obtain the specific products and enhance the efficiency of amplification. Taken together, we considered to establish a novel label based LAMP-LFA, expecting the Taq SSB protein can be efficiently used for the Cronobacter spp. detection in PIF.

Given the importance of the safety of PIF, a novel label based LAMP-LFA system was developed which was rapid and efficient to detect the target DNA of Cronobacter spp. from contaminated PIF within $40 \mathrm{~min}$. In this investigation, the specific primers designed based on the ITS gene were used to perform the LAMP reaction. Meanwhile, the specific "Fast LAMP" amplicons were achieved by the addition of Taq SSB protein to enhance the amplification efficiency and provide a novel method for rapid detection of Cronobacter spp. in the protein-rich PIF.

\section{Materials and methods}

\section{Bacterial strains, DNA extraction}

19 Cronobacter strains were utilized for specificity assays which containing 13 C. sakazakii strains (including ATCC 29544, BAA-894, NCTC 8155, SP 291, CE 13, CE 15, CE 16, CE 28, CE 29, CE 32, CE 52, CE 55 and $\mathrm{CE} 56)$ and 6 non-C. sakazakii strains. Simultaneously, 29 non-Cronobacter strains were used in this study (Table 1). C. sakazakii ATCC 29544 was used as sample to test the sensitivity in pure culture. A single clone of C. sakazakii ATCC 29544 picked from a TSA plate was incubated at $37{ }^{\circ} \mathrm{C}$ for $12 \mathrm{~h}$ in TSB (TSB, TSA without agar). After incubation, the DNA boiling extraction condition was determined. $1 \mathrm{~mL}$ of the $C$. sakazakii culture was centrifuged at $12,000 \mathrm{rpm}$ for $1 \mathrm{~min}$ (C. sakazakii collection), then the pellet was resuspended in $\mathrm{TE}_{1}$ buffer $(10 \mathrm{mM}$ Tris, $1 \mathrm{mM}$ EDTA, $\mathrm{pH}=8.0)$ and boiled at $95^{\circ} \mathrm{C}$ for $6 \mathrm{~min}$. Subsequently, the pellet was placed on ice for $7 \mathrm{~min}$ and then centrifuged at $4000 \mathrm{rpm}$ for $3 \mathrm{~min}$. The supernatant was removed to a clean tube and stored at $-20{ }^{\circ} \mathrm{C}$ for further use.

\section{Fast LAMP assay \\ Target gene and primers}

LAMP primers shown in Table 2 were designed based on the conserved sequence of the Cronobacter spp. ITS gene (GenBank: AY702093) which described previously (Hu et al. 2009). A set of 6 primers including 2 outer primers (F3 and B3), 2 inner primers (FIP and BIP) and 2 loop primers (LF and LB) which can accelerate the LAMP reaction. All the primers were synthesized commercially by Invitrogen (Shanghai, China). 
Table 1 Bacterial strains used in this investigation and the detection results of the specificity

\begin{tabular}{|c|c|c|c|c|}
\hline No. & Bacterial species & Strain & AGE & LFA \\
\hline & Cronobacter strains & & & \\
\hline 1 & C. sakazakii & ATCC 29544 & + & + \\
\hline 2 & 12 C. sakazakii & Laboratory & + & + \\
\hline 3 & C.malonaticus & DSM 18702 & + & + \\
\hline 4 & C. turicensis & DSM 18703 & + & + \\
\hline 5 & C. muytjensii & ATCC 51329 & + & + \\
\hline 6 & C. universalis & NCTC 9529 & + & + \\
\hline 7 & C. dublinensis & DSM 18705 & + & + \\
\hline \multirow[t]{2}{*}{8} & C. condimenti & LMG 26250 & + & + \\
\hline & Non-Cronobacter strains & & & \\
\hline 9 & Enterobacter cloacae & ATCC 3503 & - & - \\
\hline 10 & Enterobacter aerogenes & ATCC 13048 & - & - \\
\hline 11 & Staphylococcus aureus & CMCC 26075 & - & - \\
\hline 12 & Staphylococcus aureus & ATCC 13565 & - & - \\
\hline 13 & Staphylococcus epidermidis & ATCC 26069 & - & - \\
\hline 14 & Staphylococcus xylosus & ATCC 29971 & - & - \\
\hline 15 & Listeria monocytogenes & CMCC 54004 & - & - \\
\hline 16 & Listeria monocytogenes & CMCC 54006 & - & - \\
\hline 17 & Listeria monocytogenes & CMCC 54002 & - & - \\
\hline 18 & Listeria innocua & ATCC 33090 & - & - \\
\hline 19 & Listeria welshimeri & ATCC 43548 & - & - \\
\hline 20 & Listeria grayi & CICC 21670 & - & - \\
\hline 21 & Escherichia coli O157:H7 & ATCC 25922 & - & - \\
\hline 22 & Salmonella typhimurium & ATCC 14028 & - & - \\
\hline 23 & Salmonella enteritidis & ATCC 13076 & - & - \\
\hline 24 & Salmonella choleraesuis & CMCC 50018 & - & - \\
\hline 25 & Salmonella dublin & CMCC 50092 & - & - \\
\hline 26 & Salmonella paratyphi A & CMCC 50093 & - & - \\
\hline 27 & Salmonella enterica paratyphi B & CMCC 50094 & - & - \\
\hline 28 & Salmonella arizonae & CMCC 47020 & - & - \\
\hline 29 & Salmonella thompson & CMCC 50120 & - & - \\
\hline 30 & Salmonella pullorum & ATCC 9120 & - & - \\
\hline 31 & Pseudomonas putida & CGMCC 1.1819 & - & - \\
\hline 32 & Pseudomonas aeruginosa & ATCC 27853 & - & - \\
\hline 33 & Pseudomonas fluorescens & CGMCC 1.1802 & - & - \\
\hline 34 & Bacillus cereus & CMCC 63303 & - & - \\
\hline 35 & Shigella flexneri & CMCC 51572 & - & - \\
\hline 36 & Vibrio parahaemolyticus & ATCC 17802 & - & - \\
\hline 37 & Vibrio parahaemolyticus & ATCC 33847 & - & - \\
\hline
\end{tabular}

ATCC, American Type Culture Collection; DSM, Deutsche Sammlung von Mikroorganismen und Zellkulturen; NCTC, National Collection of Type Cultures; LMG, Belgian Coordinated Collections of Microorganisms; CMCC, National Center for Medical Culture Collections; CICC, China Center of Industrial Culture Collection; CGMCC, China General Microbiological Culture Collection; AGE, agarose gel electrophoresis; LFA, lateral flow assay; +, positive result; --, negative result

\section{Optimization of $L A M P$ reaction time}

The typical LAMP reaction assay was performed in 8 durations $(0,5,10,15,20,25,30,35,40 \mathrm{~min})$ to generate amplicons to determine the minimum detection time targeted at different concentrations of Cronobacter spp. bacteria. The amplified products were analyzed by AGE. The shortest amplification time was used to optimize the LAMP amplification assay including the concentration of dNTP, the ratio of the primers and the amplification temperature using Bst 2.0 DNA polymerase. DNA template was replaced with nuclease-free water in the negative control reaction. $2 \%$ AGE stained with EB and the LFA were used to analyze the LAMP products, respectively.

\section{Lateral flow assay \\ Preparation of AuNPs-antibody complex}

AuNPs (mean diameter, $20 \mathrm{~nm}$ ) were prepared according to the previous method (Rivas et al. 2015). The $\mathrm{pH}$ of the AuNPs suspension was adjusted to 8.3 with $0.2 \mathrm{M} \mathrm{K}_{2} \mathrm{CO}_{3}(2 \mu \mathrm{L}) .3 \mu \mathrm{L}$ of the anti-FITC antibody $(100 \mu \mathrm{g} / \mathrm{mL})$ obtained from Santa Cruz Biotechnology was added into the $1 \mathrm{~mL}$ of the adjusted colloidal gold solution with gentle stirring in dark for $15 \mathrm{~min}$. Then $10 \%$ BSA was added to the solution in dark for another $15 \mathrm{~min}$ to ensure that the colloidal gold nanoparticles were combined with the antibody and the free of gold nanoparticles were sealed. Subsequently, the mixtures were centrifuged at 10,000 rpm for $15 \mathrm{~min}$. After centrifugation, the pellet was suspended in $100 \mu \mathrm{L}$ blocking buffer $(10 \mathrm{mM}$ Tris, $1 \% \mathrm{BSA}, 2 \%$ trehalose, $\mathrm{pH}=8.0)$ and stored in a dark bottle at $4{ }^{\circ} \mathrm{C}$ until use. The AuNPantibody complex was used in the LFA.

\section{Preparation of LFA}

The composition of LFA which contained five parts (including PVC plate, sample pad, conjugate pad, absorbent pad, nitrocellulose (NC) membrane) obtained from JieYi Biotechnology was demonstrated in Fig. 1a. The sample pad was saturated with running buffer $(100 \mathrm{mM}$ Tris, $0.2 \%$ BSA, $0.05 \%$ casein, $4 \%$ trehalose, $0.5 \%$ Tween 20) for $10 \mathrm{~min}$, then dried at $42{ }^{\circ} \mathrm{C}$ for $1 \mathrm{~h}$ and stored in the refrigerator with desiccants at $4{ }^{\circ} \mathrm{C}$ for future use. The SA obtained from SigmaAldrich diluted by PB $(0.01 \mathrm{M}, \mathrm{pH}=7.4)$ to $2.5 \mathrm{mg} / \mathrm{mL}$ and goat anti-mouse IgG $(1 \mathrm{mg} / \mathrm{mL})$ purchased from Bioss (Beijing, Chian) were immobilized onto the $\mathrm{NC}$ membrane with a volume of $1 \mu \mathrm{L} / \mathrm{cm}$ to form the $\mathrm{T}$ and $\mathrm{C}$ lines, respectively. Pure cellulose fiber was used as the absorbent pad. The strips were cut into $4 \mathrm{~mm}$ width and stored in a desiccator at $4{ }^{\circ} \mathrm{C}$ for the detection of Cronobacter spp. ZX1000 Dot Dispensing Plat form XYZ3050 (BioDot, USA) and Guillotine Cutter HGS201 (Autokun, China) were used to dispense reagents and cut the strips, respectively. 
Table 2 The sequence of LAMP primers designed based on the ITS gene of Cronobacter spp.

\begin{tabular}{ll}
\hline Primer & Sequence $\left(\mathbf{5}^{\prime} \mathbf{-} \mathbf{3}^{\prime} \mathbf{)}\right.$ \\
\hline ITS-F3 & AAATGCGCGGTGTGTCAG \\
ITS-B3 & GGTTTCCCCATTCGGACAT \\
ITS-FIP & ACCGTGTACGCTTGTTCG \\
& CTTTCTCTCAAACTC \\
ITS-BIP & GCAGCAC \\
& GGCAGTCAGAGGCGA \\
ITS-LF & TGCGCCGGTATAAC \\
ITS-LB & GGTTCA \\
\hline
\end{tabular}

\section{Colorimetric detection of the LAMP amplicons with LFA}

The LAMP amplicons labeled with FITC (incorporated with the FIP primers) and biotin moieties (incorporated with the BIP primers) interact with the AuNP-antibody and SA, respectively (Fig. 1a). Then the LFA was inserted into the samples which contained $5 \mu \mathrm{L}$ of the obtained "Fast LAMP" amplicons and $100 \mu \mathrm{L}$ of running buffer. The samples were absorbed by the sample pads capillary, then passed through the $\mathrm{NC}$ membrane, finally they were captured and realized visualization. After $10 \mathrm{~min}$ later, the results were shown in the strip, in which the test line was visible due to the binding of SA to biotin in the presence of the LAMP products and the control line become visible when the goat anti-mouse IgG antibodies recognized the excess antibodies binding with the AuNPs. The evaluation of results was provided in Fig. $1 \mathrm{~b}$.
Primer dimer caused by probe-free label system

The LAMP primers $[\mathrm{C}(6,2)=15$ combination modes $]$ directly double labeled with FITC and biotin were used to test the non-specific amplification results in LFA. Briefly, all of the 15 combination modes used as negative controls without the DNA template were tested to assess self-dimerization and hetero-dimer formation. The FITC probe which conducted hybridization assay was used as the positive control with DNA template and the sequence was listed in Table 3 . All of the 15 combination modes were analyzed by LFA and AGE to determine and check the self-dimerization and hetero-dimer formation.

\section{Effect of Taq SSB protein in LAMP assay}

For eliminating the false-positive results due to nonspecific amplification of primers, the Taq SSB protein obtained from Novoprotein (Shanghai, China) was introduced to the LAMP assay. The Taq SSB protein $(0,2,4,6$, $8,10 \mathrm{ng} / \mu \mathrm{L}$ )was infiltrated into the $25 \mu \mathrm{L}$ amplification assay to test the effect for LAMP system and the analysis of results was performed by AGE. Besides, the novel label-based LAMP system was carried out in the absence and presence of Taq SSB protein to verify the effect of omitting the false-positive results using the double FITC

\section{Table 3 The sequence of FITC probe designed for labeling LAMP primer}

\begin{tabular}{ll}
\hline Primer name & Sequence $\left(5^{\prime}-\mathbf{3}^{\prime}\right)$ \\
\hline FITC probe & CTCAAACTCGCAGCACGAAGACT
\end{tabular}

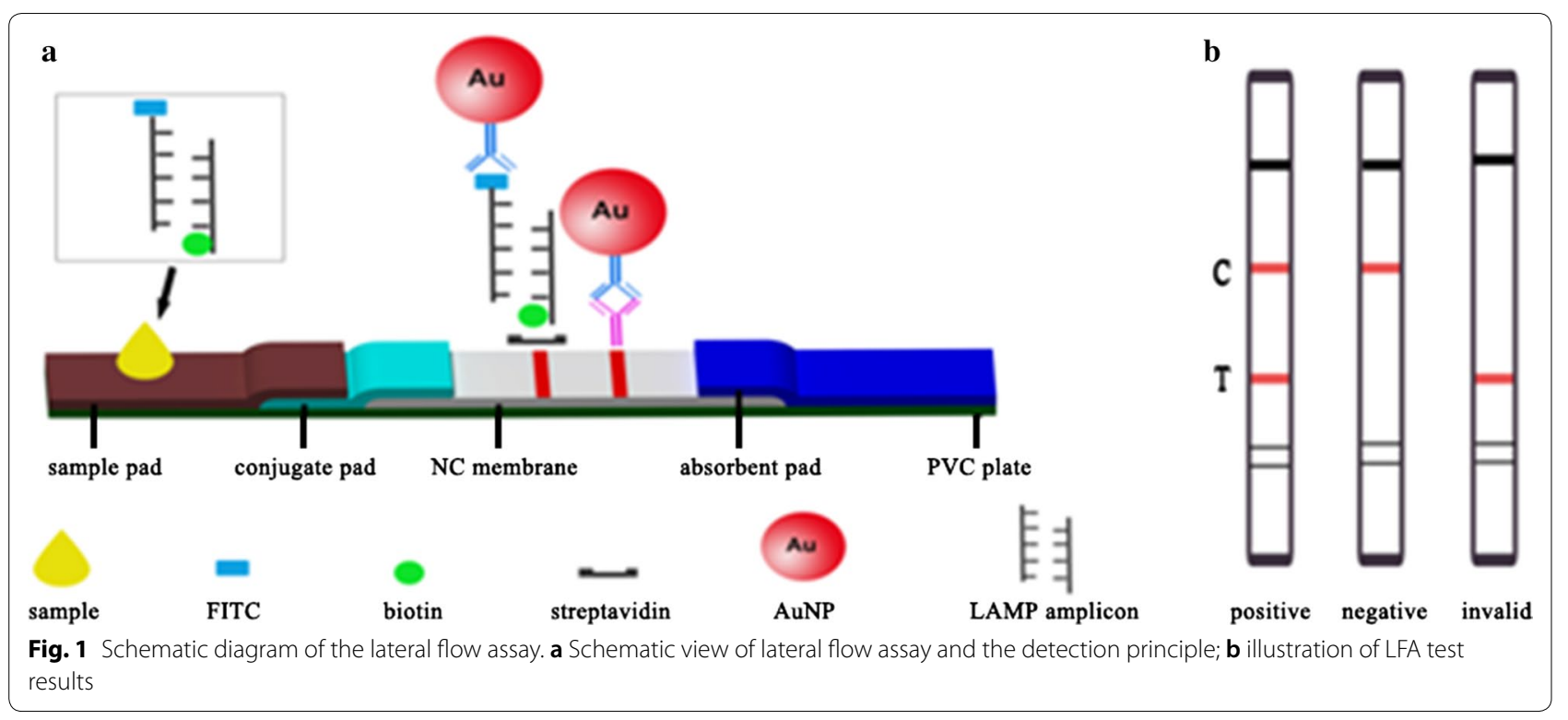


and biotin directly labeled to the mispairing primers. Tests were performed in triplicates.

\section{PCR assay}

The outer primers obtained from the LAMP primers F3 and B3 were used to perform PCR reaction and then tested for its specificity and sensitivity. The PCR reaction was conducted in a $25 \mu \mathrm{L}$ reaction mixture containing: $2 \times$ PCR Master Mix $(12.5 \mu \mathrm{L}), 10 \mu \mathrm{M}$ primer F3 and B3, DNA template $(2 \mu \mathrm{L})$ and nuclease-free water up to $25 \mu \mathrm{L}$. The cycling profile was: initial denaturation at $94{ }^{\circ} \mathrm{C}$ for $3 \mathrm{~min}, 30$ cycles of denaturation at $94{ }^{\circ} \mathrm{C}$ for $30 \mathrm{~s}$, annealing at $61{ }^{\circ} \mathrm{C}$ for $45 \mathrm{~s}$, and extension at $72{ }^{\circ} \mathrm{C}$ for $45 \mathrm{~s}$, and a final extension at $72{ }^{\circ} \mathrm{C}$ for $5 \mathrm{~min}$. Finally, the amplified $189 \mathrm{bp}-\mathrm{PCR}$ products were observed by $1 \%$ AGE stained with EB.

\section{Specificity test of LAMP-LFD}

A total of 19 Cronobacter strains containing 13 C. sakazakii strains, 6 non-C. sakazakii strains and 29 nonCronobacter strains were used to evaluate the specificity of the LAMP assay. DNA templates $(2 \mu \mathrm{L})$ obtained from the fresh overnight cultures were subjected to LAMPAGE and LAMP-LFA to test the specificity. Tests were repeated in triplicates.

\section{Sensitivity test in pure culture and in PIF}

The sensitivity in pure culture of LAMP assay was determined by using tenfold serial dilutions of the $C$. sakazakii strains. Aliquot of the $2 \mu \mathrm{L}$ extracted DNA of tenfold serial dilutions (from $4.8 \times 10^{6} \mathrm{cfu} / \mathrm{mL}$ to $4.8 \times 10^{-1} \mathrm{cfu} / \mathrm{mL}$ ) of the C. sakazakii ATCC 29544 were used as the template to perform the LAMP and PCR assay, respectively. And $2 \mu \mathrm{L}$ of nuclease-free water was used as a negative control in place of DNA. Then the PCR and LAMP products were subjected to AGE and LFA for analysis. Sensitivity tests were repeated in triplicates.

To determine the detection limit of LAMP-LFA in PIF without enrichment, $25 \mathrm{~g}$ of PIF without C. sakazakii were homogenized in $225 \mathrm{~mL}$ PBS, and then $9 \mathrm{~mL}$ of the PIF culture was inoculated with $1 \mathrm{~mL}$ of tenfold serial dilutions of C. sakazakii (ATCC 29544) culture to obtain a level of contamination from $5.6 \times 10^{5}$ to $5.6 \times 10^{0} \mathrm{cfu} / \mathrm{g}$. Subsequently, aliquot of $2 \mu \mathrm{L}$ DNA extracted from $C$. sakazakii ATCC 29544 in PIF were subjected to PCR and LAMP assay, respectively. And $2 \mu \mathrm{L}$ of nucleasefree water was used as a negative control in place of DNA. The sensitivity of the rest six Cronobacter species contaminated in PIF was tested according to the methods listed above. Then the PCR and LAMP products were subjected to LFA for analysis. Sensitivity tests were repeated three times.

\section{Results}

\section{Establishment of "Fast LAMP" assay}

As shown in Table 4, the amplicons obtained from the 25 min amplification reaction were visibly detectable for C. sakazakii at $10^{\circ} \mathrm{cfu} / \mathrm{mL}$. Ultimately, the optimized "Fast LAMP" reaction mixture $(25 \mu \mathrm{L})$ without betaine contained $1.4 \mu \mathrm{M}$ each of primers FIP and BIP, $0.2 \mu \mathrm{M}$ each of primers F3 and B3, $0.8 \mu \mathrm{M}$ each of primers LF and LB, $8 \mathrm{U}$ of Bst 2.0 WarmStart DNA polymerase, 2.5 $\mu \mathrm{L}$ of $10 \times$ ThermoPol Buffer [20 mM Tris-HCl, $10 \mathrm{mM}$ $\mathrm{KCl}, 8 \mathrm{mM} \mathrm{MgSO}$, $10 \mathrm{mM}\left(\mathrm{NH}_{4}\right)_{2} \mathrm{SO}_{4}$ and $0.1 \%$ Triton $\mathrm{X}-100$ ], $2 \mathrm{mM}$ dNTPs, $4 \mathrm{mM} \mathrm{MgSO}{ }_{4}$ and $2 \mu \mathrm{L}$ of template DNA. The optimized reaction conditions were performed in a water bath at $65{ }^{\circ} \mathrm{C}$ with the minimum of $25 \mathrm{~min}$ and terminated at $80{ }^{\circ} \mathrm{C}$ for $2 \mathrm{~min}$.

Table 4 The sensitivity study of the LAMP assay to detect Cronobacter spp. at different time periods

\begin{tabular}{|c|c|c|c|c|c|c|c|c|}
\hline \multirow{3}{*}{$\begin{array}{l}\text { Amplification time } \\
(\mathrm{min})\end{array}$} & \multicolumn{8}{|c|}{ LAMP results } \\
\hline & \multicolumn{8}{|c|}{ Colony forming unit of Cronobacter spp. (cfu/mL) } \\
\hline & $10^{-1}$ & $10^{0}$ & $10^{1}$ & $10^{2}$ & $10^{3}$ & $10^{4}$ & $10^{5}$ & $10^{6}$ \\
\hline 0 & - & - & - & - & - & - & - & - \\
\hline 5 & - & - & - & - & - & - & - & - \\
\hline 10 & - & - & - & - & - & + & + & + \\
\hline 15 & - & - & - & - & - & + & + & + \\
\hline 20 & - & - & - & + & + & + & + & + \\
\hline 25 & - & + & + & + & + & + & + & + \\
\hline 30 & - & + & + & + & + & + & + & + \\
\hline 40 & - & + & + & + & + & + & + & + \\
\hline
\end{tabular}

+ , positive result; - , negative result 


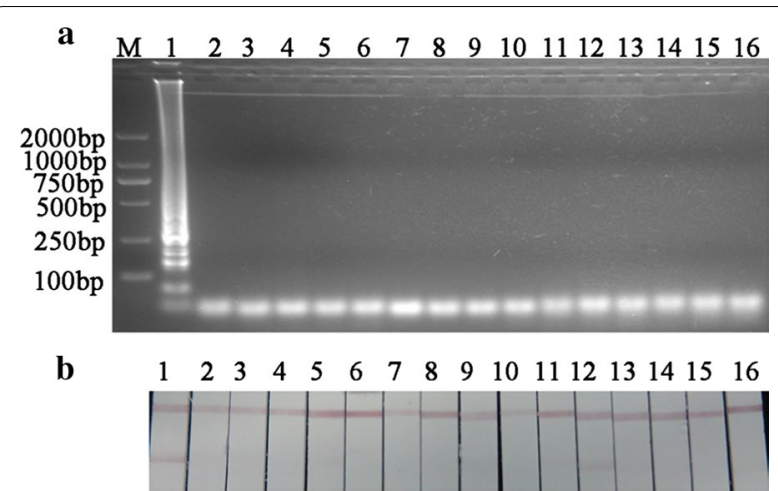

Fig. 2 The analysis of the primer dimers' location in loop-mediated isothermal amplification assay. a Agarose gel electrophoresis analysis; b lateral flow assay analysis

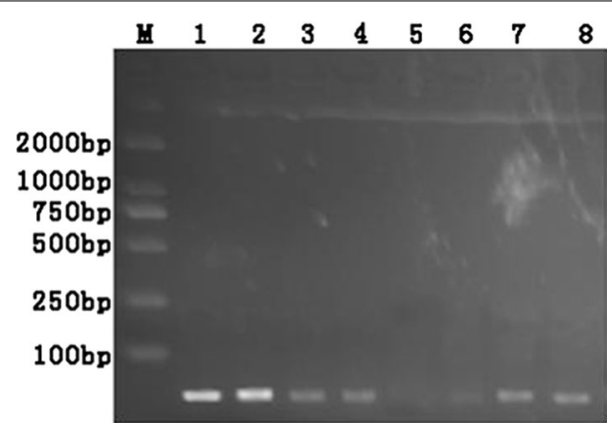

Fig. 3 The optimization of Taq SSB protein. M marker. Lanes 1-8: the concentrations of Taq SSB protein ranging from 0 to $7 \mathrm{ng} / \mu \mathrm{L}$. SSB single strand DNA binding

\section{Primer dimer caused by probe-free label system}

Using gel analysis the primers produced a stable and obvious incorrect<50-bp primer dimer. Further we found that by AGE analysis all the 15 combination modes as the negative control without DNA templates gave the negative results and the probe-hybridization assay as the positive control with DNA template provided the positive result. Compared with AGE analysis, one combination mode of F3 and LF in LAMP assay as the negative control gave an unexpected positive result by LFA analysis (Fig. 2).

\section{Effect of Taq SSB protein in LAMP assay}

As shown in Fig. 3, it was found that the most suitable concentration of Taq SSB protein introduced into the LAMP assay was $4 \mathrm{ng} / \mu \mathrm{L}$. Then the amount of LAMP primer dimer was evaluated by AGE analysis in the presence $(4 \mathrm{ng} / \mu \mathrm{L})$ or absence of Taq SSB protein. As shown in Fig. 4a (lane 1 and lane 2), a large concentration of

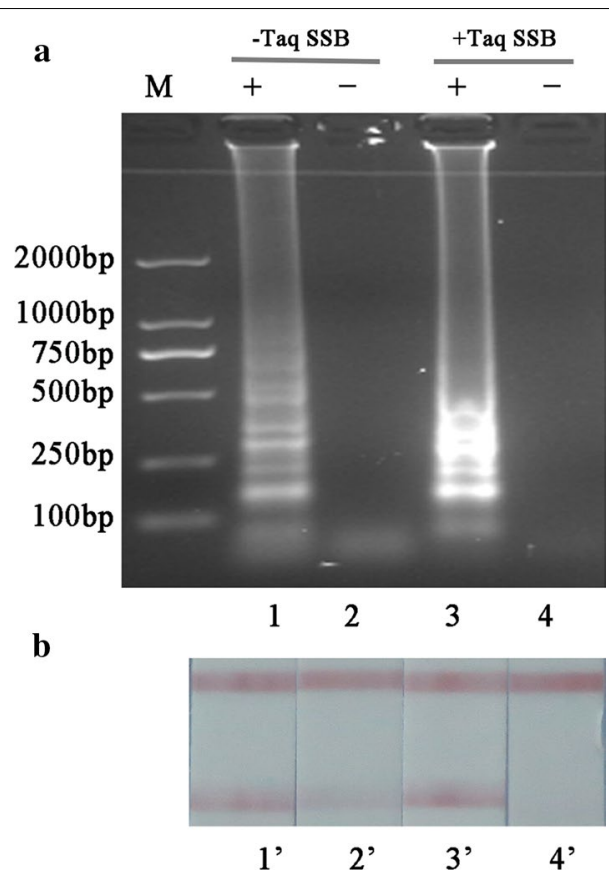

Fig. 4 The analysis of the influence of Taq SSB protein in the LAMP reaction. a Agarose gel electrophoresis analysis; $\mathbf{b}$ lateral flow assay analysis. SSB = Single strand DNA binding

dimer products was formed in the absence of Taq SSB protein. A different situation was observed in the presence of Taq SSB protein shown in lane 3 and lane 4 with a decrease in dimer products. In addition, by LFA tests the spurious results were ruled out in the presence of Taq SSB protein compared to results obtained in the absence of Taq SSB protein using the mispairing primers F3 and LF (lanes $3^{\prime}$ and $4^{\prime}$ ). The false positive results induced by primer dimer were efficiently eliminated.

\section{Specificity of LAMP-LFD assay}

19 Cronobacter spp. strains and 29 non-Cronobacter spp. strains were used to test the specificity of LAMP by the double AGE and LFA methods. Results indicated that 19 Cronobacter spp. strains gave positive results and 29 non-Cronobacter spp. strains produced negative results by AGE and LFA analysis (Table 1). Simultaneously, the structures of the positive amplified products were confirmed by DNA sequencing and the obtained sequences matched the sequences in the targeted region in the ITS of Cronobacter spp. strains perfectly. Our results shown that the established LAMP method can detect Cronobacter spp. with high specificity using the primers with an appropriate label system. 


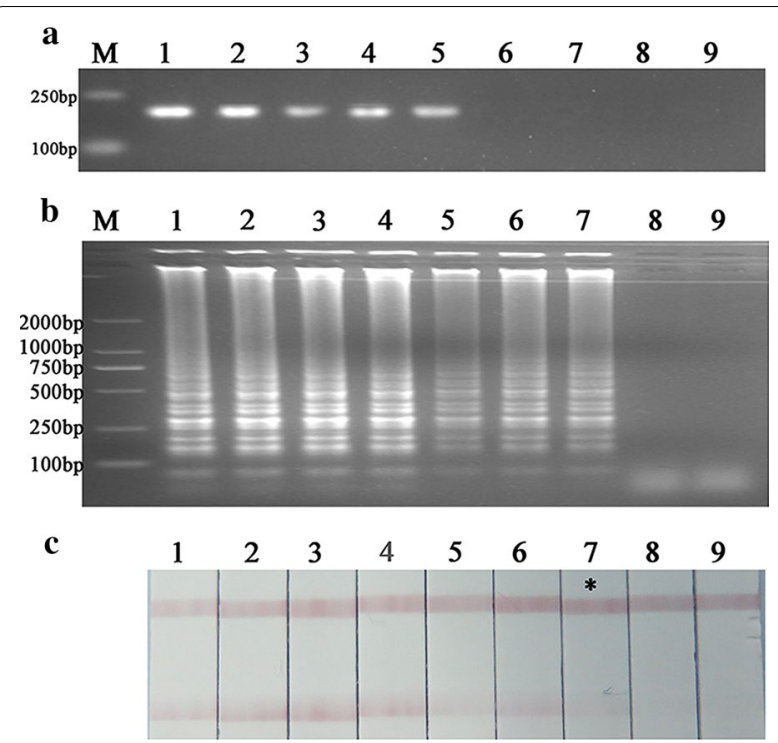

Fig. 5 The sensitivity test of Cronobacter spp. in pure culture. a PCR; $\mathbf{b}$ loop-mediated isothermal amplification-agarose gel electrophoresis (LAMP-AGE); c loop-mediated isothermal amplification-lateral flow assay (LAMP-LFA). M: marker. Lanes 1 to 8: the concentrations of Cronobacter sakazakii ATCC 29544 ranging from $4.8 \times 10^{6}$ to $4.8 \times 10^{-1} \mathrm{cfu} / \mathrm{mL}$; lane 9 , negative control

\section{Sensitivity test in pure cultures}

$4.8 \times 10^{6} \mathrm{cfu} / \mathrm{mL}$ C. sakazakii through plate counts from ATCC 29544 was ten-fold diluted to a minimum concentration equivalent to $4.8 \times 10^{-1} \mathrm{cfu} / \mathrm{mL}$. DNA was efficiently extracted from each of $C$. sakazakii dilution. The detection limit of PCR assay was $4.8 \times 10^{2} \mathrm{cfu} /$ $\mathrm{mL}$ by AGE analysis, while that of the "Fast LAMP" was $4.8 \times 10^{0} \mathrm{cfu} / \mathrm{mL}$. Simultaneously, by the novel label LFA system analysis, the detectable red color in the test line was $4.8 \times 10^{\circ} \mathrm{cfu} / \mathrm{mL}$ consistent with AGE analysis (Fig. 5). Neither of the results in the LAMP assay utilizing the nuclease-free water as negative control indicated a signal.

\section{Detection of Cronobacter spp. in PIF}

The sensitivity of detecting C. sakazakii ATCC 29544 in real PIF samples using the LAMP-LFA and LAMP-AGE was demonstrated at a limit of $5.6 \times 10^{1} \mathrm{cfu} / \mathrm{g}$ (Fig. 6) without enrichment. However, in comparison the conventional PCR assay based on F3 and B3 primers only to a minimum concentration equivalent to that of $5.6 \times 10^{3}$ $\mathrm{cfu} / \mathrm{g}$, indicating that the novel label-based LAMPLFA system was 100 times more sensitive than PCR. Meanwhile, 6 Cronobacter species contaminated in PIF exhibited the same sensitivity in Table 5. No amplification observed in the negative control with each of the method.

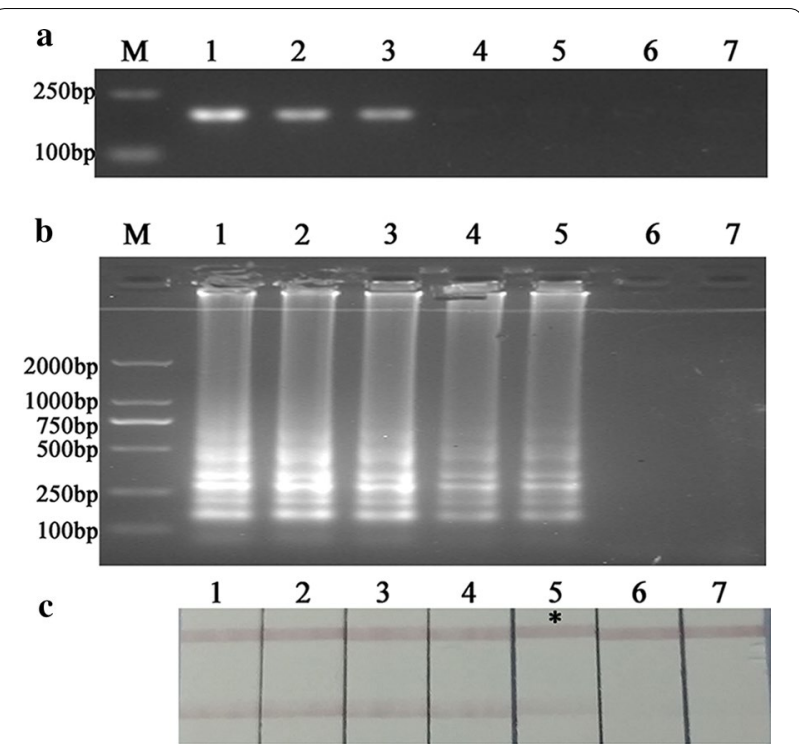

Fig. 6 The sensitivity test of Cronobacter spp. in PIF. a PCR; $\mathbf{b}$ loop-mediated isothermal amplification-agarose gel electrophoresis (LAMP-AGE); c loop-mediated isothermal amplification-lateral flow assay (LAMP-LFA). M: marker. Lanes 1 to 6: the PIF contaminated with concentrations of the Cronobacter sakazakii ATCC 29544 ranging from $5.6 \times 10^{5}$ to $5.6 \times 10^{0} \mathrm{cfu} / \mathrm{g}$. Lane 7 , negative control

Table 5 Detection limit of Cronobacter genus in PIF

\begin{tabular}{ll}
\hline Bacterial species & $\begin{array}{l}\text { Detection } \\
\text { limit (cfu/g) }\end{array}$ \\
\hline C. sakazakii & $5.6 \times 10^{1}$ \\
C. malonaticus & $2.4 \times 10^{1}$ \\
C. turicensis & $4.6 \times 10^{1}$ \\
C. muytjensii & $7.9 \times 10^{1}$ \\
C. universalis & $4.7 \times 10^{1}$ \\
C. dublinensis & $1.9 \times 10^{1}$ \\
C. condimenti & $9.2 \times 10^{1}$ \\
\hline
\end{tabular}

\section{Discussion}

Rapid and accurate detection of Cronobacter spp. was essential to control the spread of Cronobacter spp. in PIF. This report which described the evaluation of the novel probe-free LAMP method combined with LFA was more specific than the conventional PCR to detect Cronobacter spp. in PIF. In our investigation, this novel and simple strategy for LAMP-LFA detection of Cronobacter spp. with the probe-free system was based on genetically variable and species-specific $16 \mathrm{~S}-23 \mathrm{~S}$ ITS rRNA. It was found that the primers designed based on the 16S-23S rRNA showed high specificity in this probe-free label system for the detection of Cronobacter spp. Liu et al. found similar results using LAMP with ITS sequence that all of the 15 strains of Cronobacter spp. showed positive results 
while all of the 61 strains of non-Cronobacter spp. were examined to be negative results (Liu et al. 2010). It illustrated that $16 \mathrm{~S}-23 \mathrm{~S}$ ITS rRNA to be a reliable sequence for the detection of Cronobacter species and can be utilized to discriminate Cronobacter spp. from all nonCronobacter strains. Traditionally, the LAMP assay can be performed in 40-60 min to obtain favorable results based on $о т p A$ sequence, in which the detection limit in pure cultures was $10^{2} \mathrm{cfu} / \mathrm{mL}$ (Fan et al. 2012). Though this LAMP assay was free of betaine, the determined amplification time was reduced to 25 min compared to the previous amplification time. Our investigation will provide a new route to establish a LAMP assay for rapid detection.

LAMP amplicons were visualized in LFA based on the probe-label system. However, previous study demonstrated that sometimes the probe-dependent label system was time-consuming, complicated, and inaccurate (Najian et al. 2016). In addition, it may yield the falsepositive results caused by the carry-over contamination when the probe labeled with FITC was added at the end of amplification. Removal of the step of probe hybridization can avoid the incubation step before detection analysis and minimize the detection time. Here the use of FITC to label the probe and the probe incubation step before the LFA analysis were eliminated. This novel label system avoided false positives induced by the carryover contamination, exhibiting high efficiency of our results. However, the non-specific amplification due to self-dimerization and hetero-dimer formation resulted in an error-prone data analysis, demonstrating that the negative results revealed false positive results. Briefly, the detection result could be positive for non-Cronobacter spp. sample without DNA template by using the LAMP-LFA method, this may be a key impediment in application.

Although the probe-free system was described and introduced into pathogenic detection in 2016 (Najian et al. 2016), the problem of primer dimer resulting in false positives was still ignored. There was no formation of primer dimer by analysis of the self-dimerization and hetero-dimer formation when 6 LAMP primers were employed to perform the LAMP assay. However, once the presence of primer dimer tagged with markers such as FITC and biotin in the LAMP-LFA assay, the false positive results would be observed. Essentially, the primer dimer was induced by the non-specific amplification, one of the particular problems known to cause inhibition of primer hybridization to the template and reduction of a number of primers available for annealing. Also, the probe-free label system was faced with the same challenge. It was demonstrated that the FITC based probe primer released the fluorescence signals not only in the specific isothermal amplification but also in the "primer dimer" caused by the non-specific amplification (Tian et al. 2014). Thus the reduction of primer dimer in the amplification assay is of great significance. Previously, Taq SSB protein was successfully used for enhancement of PCR amplification efficiency. It enables to combine proteins with ssDNA rather than dsDNA, thus preventing the production of the secondary-structure or dimer formation due to the primer mismatches. Here we revealed that the Taq SSB protein could be acted as a powerful reagent addictive to the LAMP amplification. Application of the Taq SSB protein to the LAMP assay can significantly improve the efficiency of this amplification assay. Simultaneously, the primer dimer can be reduced to rule out the false positive results in LFA. The detection sensitivity achieved by Taq SSB protein based fast-LAMP assay increased to $10^{1} \mathrm{cfu} / \mathrm{g}$ in the protein-rich PIF. Nevertheless, results also demonstrated that the excess Taq SSB protein in LAMP assay may occupy the site of the primers and prevent the primers binding with the dsDNA template for amplification. Therefore, the appropriate concentration of Taq SSB protein can be helpfully applied to the LAMP assay in the bio-diagnostics area. The novel label-based system took advantage of Taq SSB protein to bind with the large or small fragments to eliminate spurious results of LFA and consequently provided a new method in detection. Meanwhile, Taq SSB added to LAMP reaction replaced betaine and enhanced the efficiency of amplification.

Detection of Cronobacter spp. in the complex and protein-rich PIF is a painstaking problem in the detection area. Direct application of the LFA in detecting Cronobacter spp. will be innovative. However, a major challenge is the lack of highly specific antibodies, hindering the application in detecting Cronobacter spp. based on antibody strips. In this paper, the LFA combination with LAMP was found to be sensitive and specific in monitoring Cronobacter spp. in PIF, in which the components of the running buffer and blocking buffer were determined to stabilize the LFA and maintain the detection sensitivity consistent with the AGE analysis. Commonly, Tween-20 in LFA can promote the release of gold conjugates, avoid non-specific reaction on the pad and increase the intensity of the red line (Rivas et al. 2015). The addition of BSA and trehalose can enhance the specificity and efficiency of the LFA strips. Thus, the optimized LFA simplified the operation, avoided the use of carcinogenic substances (such as EB), and minimized the detection time. Our approach provided a practical method for the diagnosis of Cronobacter spp. in PIF. Finally, this investigation demonstrated that this fast LAMP assay combined LFA is the first report to demonstrate a probe-free label system for specific detection of Cronobacter spp. 
The detection limit of LAMP-LFA based on ITS in real samples is $10^{1} \mathrm{cfu} / \mathrm{g}$, ten times more sensitive than the past efforts (Hu et al. 2009; Fan et al. 2012). As suggested by the international microbiological standards that all species of Cronobacter must be absent in $10 \mathrm{~g}$ of PIF. Although in this study the minimum culture time for the detection of Cronobacter spp. with LAMP-LFA was not mentioned, the method of less than $6 \mathrm{~h}$ enrichment and overnight can be applied to achieve the desired sensitivity (Fan et al. 2012). Therefore, the novel probe-free LAMPLFA has been demonstrated as a cost-effective, practical tool for detecting Cronobacter spp. in PIF.

In summary, our investigation revealed that the combination of the "Fast LAMP" method with LFA by probefree and specific label system was proven to be a sensitive method to detect Cronobacter genus in PIF. Simultaneously, the LAMP amplicons directly double embedded with FITC and biotin can be specifically captured by LFA, in which the false positive results due to the primer dimers were efficiently eliminated by introducing the Taq SSB protein into the LAMP assay. And the total detection time of this system was within $40 \mathrm{~min}$. We found that the sensitivity of this rapid LAMP-LFA system, which was consistent with LAMP-AGE, was 100 times higher than the traditional PCR method. It was $10^{\circ} \mathrm{cfu} /$ $\mathrm{mL}$ in pure culture while that was $10^{1} \mathrm{cfu} / \mathrm{g}$ in PIF without enrichment, respectively. Therefore, this novel labelbased LAMP-LFA with probe-free can be considered as a rapid, highly sensitive and specific tool for the detection of Cronobacter spp. in PIF, especially in limited resource settings. Simultaneously, this method could provide an advanced platform for multiplex detection in rapid detection field.

\section{Abbreviations \\ Cronobacter spp.: Cronobacter species; PIF: powdered infant formula; LAMP: loop-mediated isothermal amplification; AGE: agarose gel electrophoresis; LFA: lateral flow assay; EB: ethidium bromide; FITC: fluorescein isothiocyanate; SA: streptavidin; AuNPs: gold nanoparticles; SSB: single strand DNA binding; NC: nitrocellulose.}

\section{Authors' contributions}

$\mathrm{YJ}$ and $\mathrm{CM}$ designed the entire research project; $\mathrm{SF}$ and $\mathrm{XJ}$ designed the experimental details and performed the experiments; $X Y$ provided the required strains for the experiment; $S F$ prepared the manuscript; $Y J$ and $C M$ reviewed the manuscript; SF, XJ, YZ and SC revised the manuscript. All authors read and approved the final manuscript.

\section{Competing interests}

The authors declare that they have no competing interests.

\section{Availability of data and materials}

All data generated or analyzed during this study are included in this published article.

\section{Consent for publication}

Not applicable.
Ethics approval and consent to participate Not applicable.

\section{Funding}

This study was supported by National Natural Science Foundation of China (No. 31871828), National High-level Talents Special Support Program of China and "Academic Backbone" Project of Northeast Agricultural University (15XG26).

\section{Publisher's Note}

Springer Nature remains neutral with regard to jurisdictional claims in published maps and institutional affiliations.

Received: 13 May 2018 Accepted: 26 September 2018

Published online: 29 September 2018

\section{References}

Blažková M, Koets M, Rauch P, Amerongen AV (2009) Development of a nucleic acid lateral flow immunoassay for simultaneous detection of Listeria spp. and Listeria monocytogenes in food. Eur Food Res Technol 229(6):867-874. https://doi.org/10.1007/s00217-009-1115-z

Brownie J, Shawcross S, Theaker J, Whitcombe D, Ferrie R, Newton C, Little S (1997) The elimination of primer-dimer accumulation in PCR. Nucleic Acids Res 25(16):3235-3241. https://doi.org/10.1093/nar/25.16.3235

Cecilia D, Kakade M, Alagarasu K, Patil J, Salunke A, Parashar D, Shah PS (2015) Development of a multiplex real-time RT-PCR assay for simultaneous detection of dengue and chikungunya viruses. Arch Virol 160(1):323-327. https://doi.org/10.1007/s00705-014-2217-x

Chen Q, Tao T, Bie X, Lu Y, Lu F, Zhai L, Lu Z (2015) Mining for sensitive and reliable species-specific primers for PCR for detection of Cronobacter sakazakii by a bioinformatics approach. J Dairy Sci 98(8):5091-5101. https ://doi.org/10.3168/jds.2015-9304

Chen Y, Cheng N, Xu Y, Huang K, Luo Y, Xu W (2016) Point-of-care and visual detection of $P$. aeruginos $a$ and its toxin genes by multiple LAMP and lateral flow nucleic acid biosensor. Biosens Bioelectron 81:317-323. https ://doi.org/10.1016/j.bios.2016.03.006

Cornelissen JB, De GA, Heuvelink AE, Swarts M, Smith HE (2016) Rapid detection of Streptococcus uberis in raw milk by loop-mediated isothermal amplification. J Dairy Sci 99(6):4270-4281. https://doi.org/10.3168/ jds.2015-10683

Cruz-Córdova A, Rocha-Ramírez LM, Ochoa SA, Gónzalez-Pedrajo B, Espinosa N, Eslava C, Hernández-Chiñas U, Mendoza-Hernández G, RodríguezLeviz A, Valencia-Mayoral P, Sadowinski-Pine S, Hernández-Castro R, Estrada-García I, Muñoz-Hernández O, Rosas I, Xicohtencatl-Cortes J (2012) Flagella from five Cronobacter species induce pro-inflammatory cytokines in macrophage derivatives from human monocytes. PLoS ONE 7(12):e52091. https://doi.org/10.1371/journal.pone.0052091

Ding WC, Chen JO, Shi YH, Lu XJ, Li MY (2010) Rapid and sensitive detection of infectious spleen and kidney necrosis virus by loop-mediated isothermal amplification combined with a lateral flow dipstick. Arch Virol 155(3):385389. https://doi.org/10.1007/s00705-010-0593-4

Fan H, Long B, Wu X, Bai Y (2012) Development of a loop-mediated isothermal amplification assay for sensitive and rapid detection of Cronobacter sakazakii. Foodborne Pathog Dis 9(12):1111-1118. https://doi.org/10.1089/ fpd.2012.1193

Gautam K, Lyudmila S, Lennox KA (2015) Cronobacter species contamination of powdered infant formula and the implications for neonatal health. Front Pediatr. 3:56. https://doi.org/10.3389/fped.2015.00056

Gordon CL, Tokarz R, Briese T, Lipkin WI, Jain K, Whittier S, Shah J, Connolly ES, Yin MT (2015) Evaluation of a multiplex polymerase chain reaction for early diagnosis of ventriculostomy-related infections. J Neurosurg 123(6):1586-1592. https://doi.org/10.3171/2014.11.jns141036

Hu L, Zhang W, Zhang X, Yuan Y, Zhang Y, Zhang H, Ma X, Su X (2009) Development of a loop-mediated isothermal amplification assay for rapid detection of Enterobacter sakazakii in powdered infant formula. Acta Micro Sinica 49(3):378-382

Liu C, Zheng W, Zhang H, Hou Y, Liu Y (2010) Sensitive and rapid detection of Enterobacter sakazakii in infant formula by loop-mediated isothermal 
amplification method. J Food Saf 29(1):83-94. https://doi.org/10.111 1/j.1745-4565.2008.00142.x

Mai M, Müller I, Maneg D, Lohr B, Haecker A, Haberhausen G, Hunfeld KP (2015) Real-time PCR-based identification of bacterial and fungal pathogens from blood samples. Methods Mol Biol 1237:139-147. https://doi. org/10.1007/978-1-4939-1776-1_14

Moraes RRD, Maruniak JE (1997) Detection and identification of multiple baculoviruses using the polymerase chain reaction (PCR) and restriction endonuclease analysis. JVirol Methods 63(1-2):209-217. https://doi. org/10.1016/s0166-0934(96)02130-1

Najian ABN, Syafirah EAREN, Ismail N, Mohamed M, Chan YY (2016) Development of multiplex loop mediated isothermal amplification (m-LAMP) label-based gold nanoparticles lateral flow dipstick biosensor for detection of pathogenic Leptospira. Anal Chim Acta 903:142-148. https://doi. org/10.1016/j.aca.2015.11.015

Nimitphak T, Kiatpathomchai W, Flegel TW (2008) Shrimp hepatopancreatic parvovirus detection by combining loop-mediated isothermal amplification with a lateral flow dipstick. J Virol Methods 154(2):56-60. https://doi. org/10.1016/j.jviromet.2008.09.003

Notomi T, Okayama H, Masubuchi H, Yonekawa T, Watanabe K, Amino N, Hase T (2000) Loop-mediated isothermal amplification of DNA. Nucleic Acids Res 28(12):E63. https://doi.org/10.1093/nar/28.12.e63

Odeyemi OA, Sani NA (2016) The prevention of Cronobacter infections in hospital neonatal intensive care units. J Infect Public Health 9(1):110-112. https://doi.org/10.1016/j.jiph.2015.06.012

Rivas L, Escosura-Muñiz ADL, Serrano L, Altet L, Francino O, Sánchez A, Merkoçi A (2015) Triple lines gold nanoparticle-based lateral flow assay for enhanced and simultaneous detection of Leishmania DNA and endogenous control. Nano Res 8(11):3704-3714. https://doi.org/10.1007/s1227 4-015-0870-3
Song X, Shukla S, Lee G, Park S, Kim M (2016) Detection of Cronobacter genus in powdered infant formula by enzyme-linked immunosorbent assay using anti-cronobacter antibody. Front Microbiol. 7:e52091. https://doi. org/10.3389/fmicb.2016.01124

Susan J, Forsythe SJ (2011) Predominance of Cronobacter sakazakii sequence type 4 in neonatal infections. Emerg Infect Dis 17(9):1713-1715. https:// doi.org/10.3201/eid1709.110260

Tafelski S, Nachtigall I, Adam T, Bereswill S, Faust J, Tamarkin A, Trefzer T, Deja M, Idelevich EA, Wernecke KD (2015) Randomized controlled clinical trial evaluating multiplex polymerase chain reaction for pathogen identification and therapy adaptation in critical care patients with pulmonary or abdominal sepsis. J Int Med Res 43(3):364-377. https://doi. org/10.1177/0300060514561135

Tian L, Cronin TM, Weizmann Y (2014) Enhancing-effect of gold nanoparticles on DNA strand displacement amplifications and their application to an isothermal telomerase assay. Chem Sci 5(11):4153-4162. https://doi. org/10.1039/c4sc01393j

Wang X, Teng D, Guan Q, Tian F, Wang J (2013) Detection of Roundup Ready soybean by loop-mediated isothermal amplification combined with a lateral-flow dipstick. Food Control 29(1):213-220. https://doi.org/10.1016/j. foodcont.2012.06.007

Yan Q, Fanning S (2015) Strategies for the identification and tracking of Cronobacter species: an opportunistic pathogen of concern to neonatal health. Front Pediatr. 3:38. https://doi.org/10.3389/fped.2015.00038

Zhang L, Huang Y, Wang J, Rong Y, Lai W, Zhang J, Chen T (2015) Hierarchical flowerlike gold nanoparticles labeled immuno chromatography test strip for highly sensitive detection of Escherichia coli 0157:h7. Langmuir 31(19):5537-5544. https://doi.org/10.1021/acs.langmuir.5b00592

\section{Submit your manuscript to a SpringerOpen ${ }^{\odot}$ journal and benefit from:}

- Convenient online submission

- Rigorous peer review

- Open access: articles freely available online

- High visibility within the field

- Retaining the copyright to your article

Submit your next manuscript at $\boldsymbol{\nabla}$ springeropen.com 